\title{
Peertechz
}

\section{Designing and evaluating} analytical parameters to adapt siemens urinary creatinine enzymatic method to open system analysers

\author{
Ashraf Mina ${ }^{1,2 \star}$, Leah McNeice ${ }^{1}$, Shanmugam Banukumar ${ }^{1}$ \\ and Santiago Vazquez ${ }^{1}$
}

${ }^{1}$ NSW Health Pathology, Forensic \& Analytical Science Services (FASS), Toxicology Unit, Macquarie Hospital, NSW, Australia

${ }^{2}$ Affiliated Senior Clinical Lecturer, Faculty of Medicine and Health, Sydney University, NSW, Australia
Received: 04 September, 2020

Accepted: 16 September, 2020

Published: 17 September, 2020

*Corresponding author: Dr. Ashraf Mina, NSW Health Pathology, Forensic \& Analytical Science Services (FASS), Toxicology Unit, Macquarie Hospital, NSW, Australia, Tel: +61 $0298875666,+610403108$ 682; Fax: +6102 9805 1259;

E-mail: ashraf.mina@health.nsw.gov.au

Keywords: Creatinine; Sample validity testing; Urinary creatinine; Enzymatic creatinine

https://www. peertechz.com

\section{Check for updates}

\section{Abstract}

Urinary creatinine is measured to assess kidney function and also as part of sample validity testing in drugs of abuse. Creatinine methods based on alkaline picrate Jaffés reaction require extra cleaning on chemistry analysers to minimise any interference from picric acid and sodium hydroxide on other reagents on board. Enzymatic methods reagents are not as invasive and more specific. Siemens enzymatic method is more sensitive and specific when compared to Thermo Fisher alkaline picrate method but there were no available analytical parameters to setup the Siemens enzymatic method on Beckman-Coulter AU5800 analyser as an open system analyser. Emulating setup parameters from Siemens chemistry analysers did not work. The analytical parameters were developed through systematic testing using different settings to adopt and optimise the method. A full correlation was performed using the developed parameters with alkaline picrate method. The Deming regression weighted analysis for 438 samples showed a good correlation at a $95 \%$ confidence interval. Slope is 1.029 to $1.041, Y$-intercept when $\mathrm{X}=0.0$ is -0.9156 to -0.7481 and correlation coefficient ( $r$ ) is 0.998 . Alkaline picrate method Mean and SD is 12.059 and 7.248 respectively and for the Enzymatic method is 11.653 and 7.504 respectively. Many interferences from drugs and other substances are eliminated when using the enzymatic method and the stability of other reagents on-board improved because the reagents used in the enzymatic method are less invasive.

\section{Abbreviation}

CAPD: Continuous Ambulatory Peritoneal Dialysis; eGFR: estimated Glomerular Filtration Rate; EQAS: External Quality Assurance Scheme; GFR: the Glomerular Filtration Rate; Hb F: Hemoglobin F; IgG: Immunoglobulin G; RCPA: Royal College of Pathologists of Australasia; SD: Standard Deviation; THC: Tetrahydrocannabinol

\section{Introduction}

Creatinine is a chemical waste product that is produced from normal wear and tear on muscles metabolism and to a smaller extent by eating meat. Healthy kidneys filter creatinine and other waste products from your blood. These waste products are removed from the body through urination. Urinary Creatinine is used to assess the kidney function by measuring the glomerular filtration rate (GFR). Also, urinary creatinine is analysed as part of urine sample validity when testing for drugs of abuse. Urine creatinine is used as an indicator of urine water content and as a sample validity test for urine specimens. Large intake of fluids will increase the urine water content and decrease the creatinine level and as a result diluting the drug concentration in urine. Creatinine levels lower than reference intervals in drug testing indicate that a person has been drinking a lot of fluids and attempted to dilute the results to cover the consumed drug and its metabolites. 
The creatinine Jaffé's method (alkaline picrate method) is prone to bias because of interfering substances, which means less analytical specificity. Additionally, the Jaffé's method may represent a low risk in some patients if the estimated Glomerular Filtration Rate (eGFR) result is around the 60 $\mathrm{ml} / \mathrm{min} / 1.73 \mathrm{~m}^{2}$ decision limit, which in that case should be interpreted with caution $[1,2]$.

In patients on dialysis, when creatinine was assayed in peritoneal dialysis solutions and pure glucose solutions, the Jaffé's reaction overestimated the results due to other components of dialysis solutions, mainly calcium chloride. The specific enzymatic method is a more accurate, specific and reliable assay for creatinine kinetics through the peritoneal membrane when determined in Continuous Ambulatory Peritoneal Dialysis (CAPD) solutions [3].

Albumin, Immunoglobulin G (IgG), and Hemoglobin F ( $\mathrm{Hb} \mathrm{F}$ ) do not interfere with the enzymatic methods but they interfere with Jaffé's creatinine assays, leading to inaccuracies in eGFR that are clinically important, especially in neonates and children. Consequently, the enzymatic creatinine methods are preferred for evaluation of kidney function in pediatric patients [4]. Although Jaffé and enzymatic methods meet the analytical performance requirements in routine use, the enzymatic method performed better in measuring low creatinine levels [5]. For the above-mentioned reasons, using enzymatic creatinine as part of sample validity testing for drugs of abuse will give more reliable results.

Analytically, the enzymatic method has many advantages over Jaffé-based methods such as smaller sample size, faster sample throughput, and more specificity. Additionally, glucose, acetoacetate, and cefoxitin don't interfere with the enzymatic method, but bilirubin may cause a negative interference depending on both creatinine and bilirubin concentrations. Clinically, the enzymatic method is preferred in monitoring, neonates, diabetic ketotic patients, renal disorders patients and those receiving cephalosporins $[6,7]$. Some cephalosporinlike antibiotics interfere with Jaffé's methods [8]. Siemens enzymatic method states that patients undergoing treatment with Phenindione and Dobesilate may show falsely low results. Cefoxitin showed $-11 \%$ bias in serum creatinine at $2230 \mu \mathrm{g} / \mathrm{mL}$ ( $5.2 \mathrm{mmol} / \mathrm{L})$. These interferences may be less significant when measuring creatinine in urine by chemistry analysers because drugs are mostly metabolised when excreted in urine and also the urine sample is pre-diluted on board before analysis.

Many studies showed that the enzymatic creatinine method performed better than was better than methods based on Jaffé's reaction in terms of specificity and sensitivity [9-13]. No interference from hemolysis, lipemia, or bilirubin detected when using enzymatic creatinine methods [14].

\section{Materials and methods}

The reagents used for this evaluation and their part numbers are Thermo Fisher creatinine-detect (CDF1797), Thermo Fisher creatinine calibrator set (CDF100272), Siemens enzyme creatinine-2 (11097533), Siemens chemistry calibrator
(11099411) and Bio-Rad Liquicheck urine chemistry control levels 1 (397) and 2 (398). The analyser used is BeckmanCoulter AU5800 from Beckman-Coulter Diagnostics. There were no parameters provided by Siemens to set up the assay on open system analysers such as the Beckman-Coulter AU5800 analyser.

The author experimented with different instrument settings and different reagents volumes to set up the method and to optimise performance at different concentrations.

A full correlation was done between the established alkaline picrate method and the proposed enzymatic creatinine method. Also, Bio-Rad QC materials targets for this method were met. Additionally, samples from a national External Quality Assurance Scheme (EQAS) called Austox Urine Proficiency Program is used as another tool to verify the outcome.

Table 1: Siemens enzymatic creatinine method parameter for the Beckman-Coulte AU5800 analyser as an open system analyser.

\begin{tabular}{|c|c|}
\hline Parameter & Value \\
\hline Sample volume & $7 \mu \mathrm{L}$ \\
\hline Predilution rate & 15 \\
\hline Dilution & 0 \\
\hline Diluent bottle & Outside \\
\hline Reagent 1 volume & $80 \mu \mathrm{L}$ \\
\hline Reagent 1 dilution & 0 \\
\hline Reagent 2 volume & $27 \mu \mathrm{L}$ \\
\hline Reagent 2 volume & 0 \\
\hline Primary wavelength & $600 \mathrm{~nm}$ \\
\hline Secondary wavelength & $800 \mathrm{~nm}$ \\
\hline Method & End \\
\hline Reaction slope & + \\
\hline Measuring point- $11^{\text {st }}$ & 0 \\
\hline Measuring point-1 Last & 27 \\
\hline Measuring point- $21^{\text {st }}$ & 0 \\
\hline Measuring point-2 Last & 10 \\
\hline Correlation Factor A & 1 \\
\hline Factor for Maker A & 1 \\
\hline
\end{tabular}

The developed parameters to adopt the Siemens enzymatic creatinine method for urinary creatinine are summarised in Table 1. The rest of the other parameters are user-defined. The developed parameters would apply to the open system or open channels analysers.

\section{Results}

Acorrelation and regression analysis (specimen equivalency) between Thermo Fisher creatinine alkaline picrate method and Siemens creatinine enzymatic method were performed using weighted Deming regression analysis. The number of patients' samples analysed is 438. Figure 1 and Table 2 summarise the data analysis. 
Correlation coefficient ( $r$ ) is 0.998 . If the (r) value is greater than 0.7 , the correlation is considered strong. If between 0.5 and 0.7 , it is considered a moderate correlation. If $(r)$ value is less than 0.4 , the correlation is considered weak. The calibration curve is shown in Figure 2.

The Siemens creatinine enzymatic method was accepted according to our laboratory acceptance criteria which are no big difference in SD, the slope is 1.0 or close to one and correlation coefficient $(r)$ is more than 0.7 .

The Limit of Detection (LoD) corresponds to the lowest concentration of creatinine that can be detected with a probability of $95 \%$. LoD is $\leq 1.0 \mathrm{mg} / \mathrm{dL}(0.0884 \mathrm{mmol} / \mathrm{L})$ for urine. The measuring interval for urine is $1.00-245.00$ $\mathrm{mg} / \mathrm{dL}(0.0884$ - $21.66 \mathrm{mmol} / \mathrm{L})$. The extended measuring interval was $3674.93 \mathrm{mg} / \mathrm{dL}(324.87 \mathrm{mmol} / \mathrm{L})$. The developed Parameters is set up for the extended measuring interval to avoid multiple sample dilutions beyond the measuring interval. The imprecision of the creatinine assay for within run and between runs is $\leq 5.0 \%$ Total CV.

The results of the samples tested from a national External Quality Assurance Scheme (EQAS) Austox Urine Proficiency Program is summarised below in Table 3.

Measurement Uncertainty (MU) was calculated at different levels by multiplying each assay Standard Deviation (SD) by 1.96 to cover $95 \%$ confidence interval of the tested samples based on the recommended model of the Royal College of Pathologists of Australasia (RCPA). Table 3 shows urinary creatinine Measurement Uncertainty (MU) at four different Levels in mmol/L Table 4.

\section{Discussion}

When it comes to either assessing the renal function or sample validity testing in urine, laboratories must determine the urinary creatinine level. Normal creatinine level indicates the urine sample is undiluted, but low creatinine concentration indicates the urine sample has either been adulterated or manipulated.

Urinary creatinine clearance in urine and consequently GFR determined by Jaffé's method was less than that obtained by the enzymatic method when the serum creatinine concentration

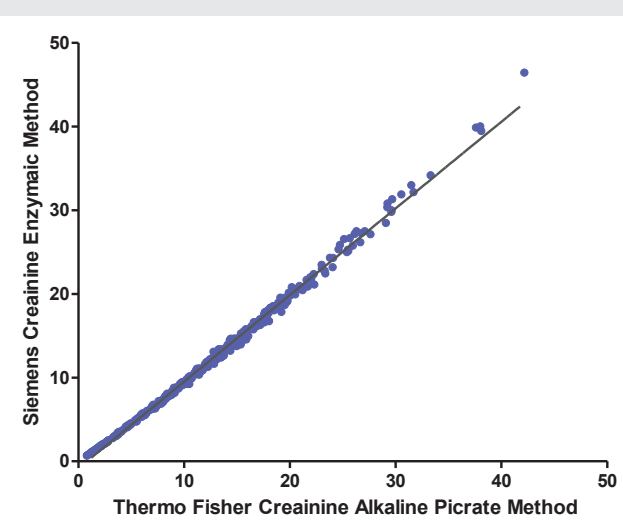

Figure 1: Deming regression analysis between Thermo Fisher creatinine alkaline picrate method and Siemens creatinine enzymatic method in $\mathrm{mmol} / \mathrm{L}$.
Table 2: Statistical analysis of the data.

\begin{tabular}{|c|c|}
\hline \multicolumn{2}{|l|}{ Best-fit values } \\
\hline Slope & $1.035 \pm 0.003029$ \\
\hline Y-intercept when $\mathrm{X}=0.0$ & $-0.8319 \pm 0.04260$ \\
\hline X-intercept & 0.8035 \\
\hline 1/slope & 0.9659 \\
\hline \multicolumn{2}{|l|}{ 95\% Confidence Intervals } \\
\hline Slope & 1.029 to 1.041 \\
\hline Y-intercept when $\mathrm{X}=0.0$ & -0.9156 to -0.7481 \\
\hline \multicolumn{2}{|l|}{ Is slope significantly non-zero? } \\
\hline $\mathrm{F}$ & 116800 \\
\hline DFn, DFd & $1.000,436.0$ \\
\hline$P$ value & $<0.0001$ \\
\hline Deviation from zero? & Significant \\
\hline \multicolumn{2}{|l|}{ Data } \\
\hline Number of $X$ values & 438 \\
\hline Maximum number of $\mathrm{Y}$ replicates & 1 \\
\hline Total number of values & 438 \\
\hline Correlation Coefficient ( $r$ ) & 0.998 \\
\hline Alkaline picrate method Mean for tested samples & 12.059 \\
\hline Enzymatic method Mean for tested samples & 11.653 \\
\hline Alkaline picrate method SD for tested samples & 7.248 \\
\hline Enzymatic method SD for tested samples & 7.504 \\
\hline
\end{tabular}

\begin{tabular}{l} 
OD \\
$\begin{array}{l}0.0300 \\
0.0240\end{array}$ \\
\hline 0.0180 \\
0.0120
\end{tabular}

Figure 2: Siemens Enzymatic method calibration curve using the Beckman-Coulter analyser

is less than $2.0 \mathrm{mg} / \mathrm{dl}$ [15]. Creatinine should be reported as "dilute" when the creatinine concentrations are equal to or more than $0.1768 \mathrm{mmol} / \mathrm{L}(2 \mathrm{mg} / \mathrm{dL})$ and less than 1.7680 $\mathrm{mmol} / \mathrm{L}(20 \mathrm{mg} / \mathrm{dL})$.

Laboratories testing for drugs of abuse should use creatinine concentration as a trigger to conduct further validity testing. If the creatinine level is less than $1.7680 \mathrm{mmol} / \mathrm{L}(20 \mathrm{mg} / \mathrm{dL})$, then the laboratory should also measure specific gravity level which should be more than 1.0010 but less than 1.0030 and $\mathrm{pH}$ is between the mmol/L intervals 4.2 to 9.0. Urine $\mathrm{pH}$ can go up to 9.5 in poor storage condition. $\mathrm{pH}$ is a measure of hydrogen ion concentration, a measure of the acidity or alkalinity of a solution. The specific gravity measures the ratio of the mass of a solution compared to the mass of an equal volume of water is an estimate of the concentration of substances dissolved in the solution. If $\mathrm{pH}$ and $\mathrm{SG}$ are flagged outside the reference interval, then urine should be tested for the presence of oxidants such as bleach or ammonia using Oxidant assay which is provided by different providers such as Thermo Fisher and Siemens. 
Table 3: The results of the samples tested from a national External Quality Assurance Scheme (EQAS) Austox Urine Proficiency Program in mmol/L.

\begin{tabular}{|c|c|c|c|c|}
\hline Laboratory Specimen Number & $\begin{array}{c}\text { Creatinine Results Using Siemens } \\
\text { Reagent on } \\
\text { Beckman-Coulter Instrument }\end{array}$ & $\begin{array}{l}\text { Creatinine Results Using } \\
\text { Siemens Reagent on } \\
\text { Siemens Atellica Instrument }\end{array}$ & $\begin{array}{c}\text { Group Mean for All Methods } \\
\text { (Austox Urine Proficiency } \\
\text { Testing) }\end{array}$ & $\begin{array}{l}\text { Group Median for ALL } \\
\text { Methods } \\
\text { (Austox Urine Proficiency } \\
\text { Testing) }\end{array}$ \\
\hline 20496 & 6.94 & 6.86 & 7.6 & 7.35 \\
\hline 20497 & 7.68 & 7.78 & 8.67 & 8.4 \\
\hline 20498 & 2.05 & 2.04 & 2.27 & 2.3 \\
\hline 28445 & 6.72 & 6.72 & 7.47 & 7.3 \\
\hline 24257 & 9.3 & 9.34 & 10.39 & 10.1 \\
\hline 24258 & 5.11 & 5.04 & 6.29 & 5.7 \\
\hline 24259 & 1.84 & 1.83 & 2.18 & 2.1 \\
\hline 28443 & 5.93 & 5.96 & 6.45 & 6.5 \\
\hline
\end{tabular}

Table 4: Urinary creatinine Measurement Uncertainty (MU) at four different levels in $\mathrm{mmol} / \mathrm{L}$.

\begin{tabular}{|c|c|c|c|c|}
\hline Urinary Creatinine Levels & $\begin{array}{c}\text { Level 1 } \\
\mathbf{m m o l} / \mathbf{L}\end{array}$ & $\begin{array}{c}\text { Level 2 } \\
\mathbf{m m o l} / \mathbf{L}\end{array}$ & $\begin{array}{c}\text { Level 3 } \\
\mathbf{m m o l} / \mathbf{L}\end{array}$ & $\begin{array}{c}\text { Level 4 } \\
\mathbf{m m o l} / \mathbf{L}\end{array}$ \\
\hline Mean & 1.13 & 3.22 & 5.89 & 13.3 \\
\hline SD & 0.08 & 0.16 & 0.30 & 0.70 \\
\hline SD x 1.96 (MU in units) & 0.16 & 0.31 & 0.59 & 1.37 \\
\hline CV\% & 2.20 & 2.30 & 2.30 & 2.40 \\
\hline CV\% x 1.96 (MU in \%) & 4.31 & 4.51 & 4.51 & 4.70 \\
\hline
\end{tabular}

The measurement of creatinine levels can be used to help in monitoring if an individual has abstained from marijuana by testing urine specimens taken a few days apart. The level of the Tetrahydrocannabinol (THC) metabolite may change from dayto-day depending on fluid intake. Consuming a large amount of fluid will lower both the THC and creatinine concentration in urine. On the other hand, dehydration will increase both concentrations. By dividing the THC result by creatinine, the result is normalised and results can be compared from different urine samples collected under different hydration or dehydration conditions.

If a dilute specimen tested positive for a drug, it should be reported as "positive dilute specimen" and is considered positive. If a dilute specimen tested negative for a drug, it should be reported as "negative dilute specimen" and is considered negative. The fact that it is a dilute specimen is irrelevant.

One study claimed that the level of interference from dextrose with enzymatic assay was greater at a higher creatinine concentration and concluded that the enzymatic assay may not be appropriate for patients using dialysate with dextrose $4.25 \%$ [16]. This study failed to mention which enzymatic method was used. The glucose reference interval in urine is 0 to 0.8 $\mathrm{mmol} / \mathrm{L}$. Siemens enzymatic creatinine package insert did not mention any interference from glucose. Also, similar methods based on the same scientific principle and chemical reaction such as Thermo Fisher enzymatic creatinine method, the package insert stated that glucose interference was tested at $139 \mathrm{mmol} / \mathrm{L}$ of glucose $(2500 \mathrm{mg} / \mathrm{dl})$ at low and high creatinine concentrations. Targeted creatinine result of $3.7 \mathrm{mmol} / \mathrm{L}$ gave a result of $5.7 \mathrm{mmol} / \mathrm{L}$ and at a higher targeted creatinine result of $25.5 \mathrm{mmol} / \mathrm{L}$, the obtained result was $24.8 \mathrm{mmol} / \mathrm{L}$.
Another study evaluated the Kodak Ektachem analyser dry-slide creatinine enzymatic method using creatinine iminohydrolase in serum found that the method had no interference from substances that interfere with Jaffe's methods such as acetoacetate, cephalothin and cephoxitin, but 5-fluorocytosine interfered significantly. The study concluded that the enzymatic method fast, specific and precision and, except for one drug when compared to Jafee's method [17].

While alkaline picrate and enzymatic creatinine methods have good precision, the enzymatic method is more precise and able to detect a biologic change in creatinine faster and consequently can detect earlier clinically significant changes when assessing renal function [18].

From practical experience, we found that due to the yellow colour of picric acid reagent used in the Jaffé's method, the cleaning of the reaction cuvettes has to be comprehensive to avoid contaminating other assays on-board. Also, the sodium hydroxide used in Jaffé's method can affect the stability of other reagents. Some drugs, such as cyclosporine were affected and its stability was reduced to only one day when the assay reagents were placed nearby Jaffé's method reagents on the analyser reagents carousels.

\section{References}

1. Schmidt RL, Straseski JA, Raphael KL, Adams AH, Lehman CM (2015) A risk assessment of the jaffe vs enzymatic method for creatinine measurement in an outpatient population. PLoS One 10: e0143205. Link: https://bit.ly/2ZI7nBI

2. Boutten A, Bargnoux AS, Carlier MC, Delanaye P, Rozet E, et al. (2013) Enzymatic but not compensated jaffe methods reach the desirable specifications of nkdep at normal levels of creatinine. Results of the french multicentric evaluation. Clin Chim Acta 419: 132-135. Link: https://bit.ly/3hz8NF2

3. Larpent L, Verger C (1990) The need for using an enzymatic colorimetric assay in creatinine determination of peritoneal dialysis solutions. Perit Dial Int 10 : 89-92. Link: https://bit.ly/3msJdoM

4. Cobbaert CM, Baadenhuijsen H, Weykamp CW (2009) Prime time for enzymatic creatinine methods in pediatrics. Clin Chem 55: 549-558. Link: https://bit.ly/2H7RUoj

5. Küme T, Sağlam B, Ergon C, Sisman AR (2018) Evaluation and comparison of abbott jaffe and enzymatic creatinine methods: Could the old method meet the new requirements? J Clin Lab Anal 32: e22168. Link: https://bit.ly/33A2kEB 
6. Crocker H, Shephard MD, White GH (1988) Evaluation of an enzymatic method for determining creatinine in plasma. J Clin Pathol 41: 576-581. Link: https://bit.ly/3mlturs

7. Goren MP, Osborne S, Wright RK (1986) A peroxidase-coupled kinetic enzymatic procedure evaluated for measuring serum and urinary creatinine. Clin Chem 32: 548-551. Link:

8. Kroll MH, Koch TR, Drusano GL, Warren JW (1984) Lack of interference with creatinine assays by four cephalosporin-like antibiotics. Am J Clin Pathol 82: 214-216. Link: https://bit.ly/35DAREV

9. Qiu L, Guo X, Zhu Y, Shou W, Gong M, et al. (2013) Effect of picric acid and enzymatic creatinine on the efficiency of the glomerular filtration rate predicator formula. Clin Lab 59: 511-522. Link: https://bit.ly/3c6x9Ve

10. Harmoinen AP (1996) Bilirubin and metamizol do not interfere with the randox enzymatic creatinine test. An evaluation of a new enzymatic creatinine determination method. Eur J Clin Chem Clin Biochem 34: 975-976. Link: https://bit.ly/35C9wmw

11. Schoenmakers CH, Kuller T, Lindemans J, Blijenberg BG (1993) Automated enzymatic methods for creatinine measurement with special attention to bilirubin interference. Eur J Clin Chem Clin Biochem 31: 861-868. Link: https://bit.ly/32xMZ8x

12. Lindbäck B, Bergman A (1989) A new commercial method for the enzymatic determination of creatinine in serum and urine evaluated: Comparison with a kinetic jaffé method and isotope dilution-mass spectrometry. Clin Chem 35 : 835-837. Link: https://bit.ly/3icXc9m
13. Guder WG, Hoffmann GE, Hubbuch A, Poppe WA, Siedel J, et al. (1986) Multicentre evaluation of an enzymatic method for creatinine determination using a sensitive colour reagent. J Clin Chem Clin Biochem 24: 889-902. Link: https://bit.ly/3kieOYf

14. Badiou S, Dupuy AM, Descomps B, Cristolead JP (2003) Comparison between the enzymatic vitros assay for creatinine determination and three other methods adapted on the olympus analyzer. J Clin Lab Anal 17: 235-240. Link: https://bit.ly/3bZXx3b

15. Horio M, Orita Y (1996) Comparison of jaffé rate assay and enzymatic method for the measurement of creatinine clearance. Nihon Jinzo Gakkai Shi 38: 296 299. Link: https://bit.ly/3mINYQN

16. Kaitwatcharachai C, Kaitwatcharachai S, Aeden J, Wiriyasombat D (2011) The glucose interference in creatinine measurement using an enzymatic method: Effect of creatinine concentrations. J Med Assoc Thai 94 Suppl 4: S131-S134. Link: https://bit.ly/3c3oxif

17. Toffaletti J, Blosser N, Hall T, Smith S, Tompkins D (1983) An automated dryslide enzymatic method evaluated for measurement of creatinine in serum. Clin Chem 29: 684-687. Link: https://bit.ly/2Fn3n2Z

18. Toffaletti JG, Hammett-Stabler CA, Gearhart M, Roy Choudhury K, Handel EA (2016) The analytical change in plasma creatinine that constitutes a biologic/ physiologic change. Clin Chim Acta 459: 79-83. Link: https://bit.ly/3bYYFE6

\section{Discover a bigger Impact and Visibility of your article publication with} Peertechz Publications

\section{Highlights}

* Signatory publisher of ORCID

* Signatory Publisher of DORA (San Francisco Declaration on Research Assessment)

* Articles archived in worlds' renowned service providers such as Portico, CNKI, AGRIS, TDNet, Base (Bielefeld University Library), CrossRef, Scilit, J-Gate etc.

* Journals indexed in ICMJE, SHERPA/ROMEO, Google Scholar etc.

* OAI-PMH (Open Archives Initiative Protocol for Metadata Harvesting)

* Dedicated Editorial Board for every journal

* Accurate and rapid peer-review process

* Increased citations of published articles through promotions

* Reduced timeline for article publication

Submit your articles and experience a new surge in publication services (https://www.peertechz.com/submission).

Peertechz journals wishes everlasting success in your every endeavours.

Copyright: ( 2020 Mina A, et al. This is an open-access article distributed under the terms of the Creative Commons Attribution License, which permits unrestricted use, distribution, and reproduction in any medium, provided the original author and source are credited. 